\title{
Major motor and gait deficits with sexual dimorphism in a Shank3 mutant mouse model
}

\author{
Emmanuel Matas ${ }^{1 \dagger}$, Alexandre Maisterrena ${ }^{1+}$, Mathieu Thabault ${ }^{1}$, Eric Balado ${ }^{1}$, Maureen Francheteau', \\ Anais Balbous ${ }^{1,2}$, Laurie Galvan ${ }^{1}$ and Mohamed Jaber ${ }^{1,2^{*}}$ (D)
}

\begin{abstract}
Background: Contrasting findings were reported in several animal models with a Shank3 mutation used to induce various autism spectrum disorder (ASD) symptoms. Here, we aimed at investigating behavioral, cellular, and molecular consequences of a C-terminal (frameshift in exon 21) deletion in Shank3 protein in mice, a mutation that is also found in clinical conditions and which results in loss of major isoforms of Shank3. A special focus was made on cerebellar related parameters.
\end{abstract}

Methods: All three genotypes were analyzed [wild type (WT), heterozygote (Shank3+/ $\Delta C$ ) and homozygote (Shank3 $\Delta C / \Delta C)$ ] and males and females were separated into two distinct groups. Motor and social behavior, gait, Purkinje cells (PC) and glutamatergic protein levels were determined. Behavioral and cellular procedures used here were previously validated using two environmental animal models of ASD. ANOVA and post-hoc analysis were used for statistical analysis.

Results: Shank3 $\Delta C / \Delta C$ mice showed significant impairments in social novelty preference, stereotyped behavior and gait. These were accompanied by a decreased number of PC in restricted cerebellar sub-regions and decreased cerebellar expression of mGluR5. Females Shank3 $\Delta C / \Delta C$ were less affected by the mutation than males. Shank3+/ $\Delta C$ mice showed impairments only in social novelty preference, grooming, and decreased mGluR5 expression and that were to a much lesser extent than in Shank3 $\Delta C / \Delta C$ mice.

Limitations: As Shank3 mutation is a haploinsufficiency, it is of interest to emphasize that Shank3+/ $\Delta \mathrm{C}$ mice showed only mild to no deficiencies compared to Shank3 $\triangle C / \Delta C$.

Conclusions: Our findings indicate that several behavioral, cellular, and molecular parameters are affected in this animal model. The reported deficits are more pronounced in males than in females. Additionally, male Shank3 $\Delta C / \Delta C$

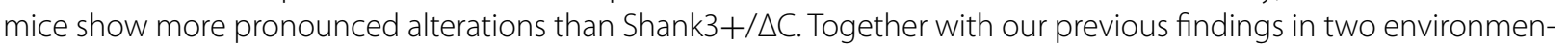
tal animal models of ASD, our studies indicate that gait dysfunction constitutes a robust set of motor ASD symptoms that may be considered for implementation in clinical settings as an early and quantitative diagnosis criteria.

Keywords: Gait, Sociability, Motor coordination, Cerebellum, Crus I, Crus II, Purkinje cells, mGluR5

*Correspondence: mohamed.jaber@univ-poitiers.fr

${ }^{\dagger}$ Emmanuel Matas and Alexandre Maisterrena have contributed equally to this work

${ }^{1}$ Université de Poitiers, INSERM, Laboratoire de Neurosciences Expérimentales et Cliniques, 86073 Poitiers, France

Full list of author information is available at the end of the article

\section{Background}

Autism spectrum disorder (ASD) is a set of heterogeneous neurodevelopmental alterations characterized by persistent difficulties in verbal and nonverbal communication with restricted and repetitive patterns of behavior [1]. ASD can be diagnosed during childhood and affects 3 times more males than females [2]. The basis for the original author(s) and the source, provide a link to the Creative Commons licence, and indicate if changes were made. The images or other third party material in this article are included in the article's Creative Commons licence, unless indicated otherwise in a credit line to the material. If material is not included in the article's Creative Commons licence and your intended use is not permitted by statutory regulation or exceeds the permitted use, you will need to obtain permission directly from the copyright holder. To view a copy of this licence, visit http://creativecommons.org/licenses/by/4.0/. The Creative Commons Public Domain Dedication waiver (http://creativeco mmons.org/publicdomain/zero/1.0/) applies to the data made available in this article, unless otherwise stated in a credit line to the data. 
male bias in ASD is unknown with theories including the "extreme male brain", hormonal differences, and genetic influences [3]. For instance, increased levels of testosterone have been correlated with autistic traits in toddlers and young children [4]. Male bias in ASD and intellectual disability have also been associated with rare mutations at chromosome Xp22.11 but that affect less than 1\% of patients [5]. In the absence of biological markers, ASD is currently diagnosed based on clinical scales focused on behavioral symptoms. There is presently no cure for ASD but only symptomatic relief to some of its comorbidities such as anxiety, sleep disorders, or seizures [6].

ASD etiology remains elusive, and both genetic and environmental components have been identified [7]. Genetic factors have long been suspected to be involved in ASD, as this is a highly heritable psychiatric disorder [8]. Hundreds of genetic mutations have been associated with ASD in genes such as neurexin (NRXN), neuroligin (NLGN), SH3 and multiple ankyrin repeat domains proteins (SHANK), tuberous sclerosis (TSC) $1 / 2$ and fragile $\mathrm{X}$ mental retardation (FMR)1, each one contributing to only a small percentage of the disease [9]. Although these mutations only account for approximately $20-30 \%$ of ASD cases, many of them seem to converge towards synaptic dysfunction as they are implicated in the formation, the function, and maintenance of synapses, mainly glutamatergic $[10,11]$. Based on these findings, the current working hypothesis is that synaptic dysfunction would lead to functional and cognitive impairments observed in ASD [12].

Several genetic mutations linked to these genes have been modeled in mice and were shown to induce behavioral symptoms reminiscent of ASD: deficits in social interaction, impairments in communication, and dysfunctional behaviors [12]. Among these mutations, Shank3 has received a great deal of attention this last decade [13-15]. Shank (also known as ProSAP) proteins consist of three major isoforms (Shank1, Shank2, and Shank3), and are master scaffolding proteins at excitatory synapses $[13,14]$. They interact with more than 30 synaptic proteins through multiple domains and are essential for synaptic formation, glutamate receptor trafficking, and neuronal signaling.

The Shank3 gene has 22 exons that give rise to numerous mRNA and protein isoforms deriving from multiple intragenic promoters and alternative splicing [11, 13]. Mouse models bearing mutations or deletions in these isoforms have been generated and have been extensively studied this last decade [16]. Although many of these animal models exhibit autism-associated behaviors, such as social deficits and repetitive behaviors, they do so to different extents and with a great deal of variability in terms of neuropathology and behavior [17-27]. These myriad outcomes can be linked to (1) the existence of several Shank3 animal models in relation with the targeted isoform, (2) lack of systematic use of heterozygote mice, whereas several Shank3 mutations are in fact a haploinsufficiency in clinical settings, (3) lack of systematic use of female mice in some of these studies and even mixing females with males within the same group of mice, (4) and lack of standardized and robust behavioral procedures.

Here, we aimed at investigating the consequences of a Shank3 mutation on behavioral parameters that we previously investigated in two different environmental animal models of ASD [28, 29]. These models were obtained following prenatal injection of either valproic acid (Depakine), an anti-epileptic drug targeting the GABA neurotransmission system, or a double stranded RNA (poly IC) mimicking a viral infection and inducing a maternal immune activation. We previously reported that these models recapitulate several ASD symptoms, although at different degrees and magnitude, with a clear sexual dimorphism. Using a full-scale behavioral analysis, we have shown in the VPA model that males and females were differently affected by the treatment with males showing motor, gait and social deficiencies while females showing only motor and gait deficiencies with normal social behavior. At the cellular level, decreased number of cerebellar Purkinje cells (PC) did not affect the same cerebellar sub-regions in males and females. Similar results were obtained with the poly IC injection, although at lower magnitude, where males were also more affected by the treatment than females. These findings recapitulate the spectrum distribution of ASD that affect differently patients in magnitude and in symptomatology with a clear sexual dimorphism.

In line, we investigate here behavioral, cellular, and molecular consequences of lack of Shank3 expression [17]. In this animal model Shank3 is lacking the entire C-terminal region, including the Homer-binding site in the sterile alpha motif (SAM) domain. This results in a partial or total loss of the major naturally occurring isoforms of Shank3 proteins in heterozygotes and homozygotes, respectively. This mutation was chosen as it has strong construct validity given that it mimics a human mutation, which is not the case of several other Shank3 mutations in mice. Major behavioral deficits were reported in these mice, including social preference deficits and repetitive behaviors, but not always using both

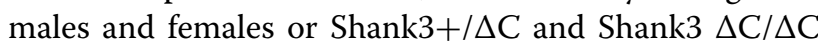
mice [22-25]. Here we used wild type, Shank3 $+/ \Delta C$, and Shank3 $\Delta C / \Delta C$ mice, and we analyzed males and females separately. A special focus was made on cerebellar-related parameters as we have previously shown that motor dysfunction and gait deficits are strongly correlated with the 
degree of severity of ASD in terms of social symptoms and loss of PC. Standardized behavioral procedures were used and were previously validated in two environmental models of ASD using a prenatal injection of either valproic acid (VPA) or the double-stranded RNA Poly: IC, inducing a maternal immune activation (MIA) [28, 29].

We report here that loss of major Shank3 isoforms induces several social, motor, and gait behavioral phenotypes reminiscent of ASD symptoms in humans. These are accompanied by a restricted decrease in both cerebellar PC cell number and mGluR5 levels. While social interaction deficits were observed in Shank $3 \Delta C / \Delta C$ and Shank $3+/ \Delta C$, in both males and females, other parameters investigated affected mostly male Shank3 $\Delta C / \Delta C$ mice.

\section{Methods}

\section{Design, and setting}

Shank3 $+/ \Delta C$ mice with a C-terminal deletion of Shank3 at exon 21 (Shank3tm1.1Pfw/J) were obtained from Jackson laboratories and are on a C57BL/6J genetic background (Jackson Laboratories, USA); they were originally donated by Paul Worley from Johns Hopkins University School of Medicine [17]. Shank3 $+/ \Delta C$ mice were mated to generate all mice of all three genotypes: WT, Shank3 $+/ \Delta C$, and Shank3 $\Delta C / \Delta C$. Sex and age-matched pups were separated from the dams on postnatal day 28 (P28) and were then genotyped and raised by groups of 4 of the same genotype in a randomized fashion to avoid litter effects. All litters of the three genotypes and two sexes were used for this study. Outliers and mice that did not perform a given test appropriately (not finishing the walking beam, jumping out of the apparatus, stalling or reversing during gait...) were taken out from the study. Comprehensive behavioral screening was performed between postnatal days 50 and 60 (P50 and P60) as we previously described in two environmental ASD mouse models $[28,29]$. Mice were tested during their light cycle and the investigators were blind to genotype. At the end of the behavioral experiments, mice were sacrificed and brains were harvested for histological analysis, RT-PCRq, or western blotting experiments.

\section{Animals}

Animal housing and experimental procedures were performed under the European Union directive (2010/63/ $\mathrm{EU})$ and validated by the regional ethical committee (Approval \# 2015020415093780). Mice were housed in ventilated cages with access to food and water ad libitum. Room temperature was maintained at $23{ }^{\circ} \mathrm{C}$ on a $12 \mathrm{~h}$ light/dark cycle. Offspring were segregated into 6 different groups: wild type males $(n=47)$, Shank $3+/ \Delta C$ males $(n=71)$, Shank3 $\Delta \mathrm{C} / \Delta \mathrm{C}$ males $(n=27)$, wild type females $(n=39)$, Shank3 $+/ \Delta C$ females $(n=58)$ and Shank3 $\Delta C /$ $\Delta \mathrm{C}$ females $(n=26)$. A set of these mice was used for every procedure, as detailed below.

\section{Behavioral analysis}

All behavioral tests were performed as we previously described in detail in two different environmental ASD mice models $[28,29]$.

Social interaction was assessed using the threechambers test (3-CT) in an apparatus that consists of a Plexiglass box $(60 \times 45 \times 22 \mathrm{~cm})$ partitioned into three chambers with retractable doorways. Mice were monitored using an unbiased automated video tracking system (VideoTrack, Viewpoint-France) which calculates several parameters for each observed animal such as position, speed, trajectory, and various other behaviors set up by the experimenter. Data were retrieved using the VideoTrack 3.2 software (Viewpoint-France). Mice were habituated to the 3-CT for 20 min 2 days before phase 1 that consists of two identical non-social stimuli (inverted wire-cups) placed in the opposite chambers. The second phase comprises a non-social stimulus and a social stimulus (a naïve mouse with no previous contact with the tested mouse). The naive mouse is of the same sex and age and is usually used for two tests per day at the most, with a $2-3 \mathrm{~h}$ rest between tests; no mouse is used more than 2 consecutive days. In the third phase, an additional and novel mouse was placed in the cup present in the opposite chamber. After a habituation phase of $10 \mathrm{~min}$ in the central chamber, mice underwent the three phases of the experiment, with each phase being of 10 min each during which time spent in each chamber and around each cup was recorded. Mice used for this procedure were Wild type males $(n=13)$, Shank $3+/ \Delta \mathrm{C}$ males $(n=20)$, Shank $3 \mathrm{C} / \Delta \mathrm{C}$ males $(n=18)$, wild type females $(n=14)$, Shank3 $+/ \Delta C$ females $(n=12)$, Shank3 $\Delta \mathrm{C} / \Delta \mathrm{C}$ females $(n=16)$.

Spontaneous grooming behavior was scored in mice placed individually in a clean and transparent cylinder with house bedding. Each mouse was videotaped and rated for $10 \mathrm{~min}$. Cumulative time spent grooming and grooming frequency were evaluated. Wild type males $(n=20)$, Shank $3+/ \Delta C$ males $(n=12)$, Shank3 $\Delta C / \Delta C$ males $(n=7)$, wild type females $(n=12)$, Shank $3+/ \Delta C$ females $(n=12)$, Shank3 $\Delta \mathrm{C} / \Delta \mathrm{C}$ females $(n=13)$.

Motor coordination was evaluated using the challenging beam test and which consists of four Plexiglass sections $(25 \mathrm{~cm}$ each) starting with a width of $3.5 \mathrm{~cm}$ and gradually narrowed to 0.5 by $1 \mathrm{~cm}$ decrements. Mice were first trained for 2 days to traverse the beam, starting at the widest section and ending at the narrowest section that led into the home cage. On the test day, a mesh grid ( $1 \mathrm{~cm}$ squares) was placed over the beam surface. Mice 
were videotaped while traversing the grid-surfaced beam for five trials. Mice that stalled during the beam walk or tried to reverse course were not included in the final analysis. Time to traverse, errors, number of steps, and errors per step made by each mouse were measured and averaged. Wild type males $(n=10)$, Shank $3+/ \Delta C$ males $(n=20)$, Shank3 $\Delta \mathrm{C} / \Delta \mathrm{C}$ males $(n=14)$, wild type females $(n=14)$, Shank3+/ $\Delta \mathrm{C}$ females $(n=17)$, Shank3 $\Delta \mathrm{C} / \Delta \mathrm{C}$ females $(n=12)$.

Gait was analyzed during spontaneous walk using an automated gait analysis system (Gaitlab, Viewpoint, France). The apparatus is made of a $1.5 \mathrm{~m}$ long glass corridor with dim green light beamed into the glass walkway. Each mouse was assessed individually for 3 consecutive runs. Mice that stalled during the beam walk or tried to reverse course were not included in the final analysis. All gait parameters were analyzed with a special focus on (1) stride length: distance between two consecutive placements of the same paw, (2) limb base of support: distance between two pair prints at contact during each step cycle, and (3) pair gap: gap between the placement of the two trailing feet, which measures spatial coordination between the two pairs. Wild type males $(n=11)$, Shank3+/ $\Delta \mathrm{C}$ males $(n=27)$, Shank3 $\Delta \mathrm{C} / \Delta \mathrm{C}$ males $(n=15)$, wild type females $(n=11)$, Shank $3+/ \Delta C$ females $(n=21)$, Shank3 $\Delta \mathrm{C} / \Delta \mathrm{C}$ females $(n=12)$.

\section{Tissue processing and immunohistochemistry}

Males and females from each genotype were randomly selected for either histological, mRNA, or protein analysis. For histological analysis, mice (wild type males

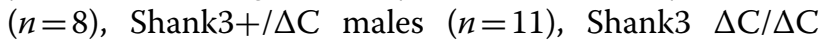
males $(n=8)$, wild type females $(n=8)$, Shank3+/ $\Delta C$ females $(n=9)$, Shank3 $\Delta C / \Delta C$ females $(n=6))$ were deeply anesthetized with ketamine-xylazine (120-20 mg/ $\mathrm{kg}$ ) and transcardially perfused with $0.9 \%$ saline at $37^{\circ} \mathrm{C}$ followed by $4 \%$ paraformaldehyde (PFA) at $4{ }^{\circ} \mathrm{C}$. Brains were post-fixed in $4 \%$ PFA at $4{ }^{\circ} \mathrm{C}$ for $24 \mathrm{~h}$ before cryoprotection in $30 \%$ sucrose for $48 \mathrm{~h}$. Serial $50 \mu \mathrm{m}$ (cerebellum) free-floating sections were collected and stored at $-20{ }^{\circ} \mathrm{C}$ until use in an anti-freeze solution. Every fourth cerebellar section was mounted on gelatin-coated slides for PC quantification. PC were identified based on their morphology on cresyl violet staining. The PC phenotype was confirmed using calbindin immunohistochemistry (1:2500; Swant, Cb-38a) [30]. Stereological estimates were performed using the optical fractionator method and systematic random sampling to obtain the total number of cerebellar PC. Each region of interest was outlined based on the Franklin and Paxinos's mouse brain atlas [31] at $2.5 \times$ objective. Neurons were counted at $40 \times$ objective using the Mercator image analysis system (Explora Nova, France). Upper and lower guard zones of $1 \mu \mathrm{m}$ were set at the top and bottom of the section to exclude lost profiles and each neuron or visible nucleus was counted as previously described [28, 29].

\section{Quantitative immunoblot analysis}

Mice from each group [wild type males $(n=4)$, Shank3+/ $\Delta \mathrm{C}$ males $(n=8)$, Shank $3 \mathrm{C} / \Delta \mathrm{C}$ males $(n=8)$, wild type females $(n=5)$, Shank3+/ $\Delta \mathrm{C}$ females $(n=8)$, Shank3 $\Delta \mathrm{C} / \Delta \mathrm{C}$ females $(n=9)]$ were sacrificed, brains were retrieved, and cerebellum region was dissected out and frozen in - $80 \mathrm{C}$ until use. For control purposes, we also used cerebella obtained from offspring of pregnant mice that received VPA injections at E12.5, as previously described [28]. Proteins were extracted using a $1 \%$ sodium dodecyl sulfate (SDS) solution in Tris $\mathrm{Hcl} 0.1 \mathrm{M}$ with EDTA $0.01 \mathrm{M}$ and PMSF, protease inhibitor, and phosphatase inhibitor at 1\%. Equal amounts of proteins from cerebellum lysates were separated by SDS-PAGE and migrated proteins were transferred to nitrocellulose membranes (Bio-Rad). After blocking the membranes at room temperature for $1 \mathrm{~h}$ in Tris Buffer Solution with Tween-20 0,1 M (TBST) and (pH 7.4, TBS) 5\% non-fat milk, the blots were incubated with corresponding primary antibodies at room temperature for $3 \mathrm{~h}$. The blots were then washed three times in TBST and incubated with HRP-conjugated secondary antibodies overnight at $4{ }^{\circ} \mathrm{C}$. Following 3 washes in TBST, the blots were incubated with ECL reagent (GE Healthcare Life Sciences, NJ, USA). For quantification, the films were scanned by a PXi image system and gray signals were analyzed by GeneTools software (Syngene, Cambridge, UK), and normalized to that of corresponding internal controls (actin or $\beta$-tubulin III). The primary antibodies mTOR 7C10, P-mTOR ser 2448, ERK1/2, and P-ERK1/2 (Cell Signaling Technology, Leiden, The Netherlands) were used at the dilution $1 / 1000$ to $1 / 1500$. NR2A, NR2B, GluR1, and GAPDH antibodies (Millipore, Paris, France) were used at the dilution of $1 / 500$ to $1 / 1500$. The following dilutions were used for antibodies against CAMKII (1/1000), $\alpha$-tubulin $(1 / 10,000)$, and $\beta$-actin $(1 / 10,000)$ (SigmaAldrich, Lyon, France). Shank3 and mGluR5 antibodies (Abcam, Paris, France) were used at the dilution of 1/500 and 1/5000, respectively. NR1 antibodies (Antibodies Incorporated, California, USA) were used at the dilution of 1/500. GluR2 antibodies (Neuromab, California, USA) were used at the dilution of $1 / 1000$.

\section{RT-PCRq analysis of mGluR5 mRNA levels}

Mice from each group (wild type males $(n=7)$, Shank3+/ $\Delta \mathrm{C}$ males $(n=8)$, Shank3 $\Delta \mathrm{C} / \Delta \mathrm{C}$ males $(n=8)$, wild type females $(n=7)$, Shank3+/ $\mathrm{C}$ females $(n=8)$, Shank3 $\Delta C / \Delta C$ females $(n=8))$ were sacrificed, brains were retrieved, and cerebellum region was dissected out 
and frozen in -80C until use. Total RNA was isolated using TRIzol Reagent/chloroform, then purified using a NucleoSpin RNA kit (Macherey-Nagel) and quantified using NanoDrop ND-1000 spectrophotometer (Thermo Fisher Scientific, USA). Reverse transcription was performed on $1 \mu \mathrm{g}$ of total RNA for each sample using Verso cDNA Synthesis kit (Thermo Fischer Scientific). qPCR was performed on LightCycler 480 system (Roche Diagnostics, France). Ct values were averaged from triplicates. Results were subtracted to the mean $\mathrm{Ct}$ of the housekeeping genes Gapdh, Beta actin and cyclophilin A $(\Delta \mathrm{Ct})$ and log transformed $\left(2^{-\Delta \mathrm{Ct}}\right)$. mGluR5 primers sequence was designed using Primer-Blast (NCBI); primers were synthesized by IDT: $5^{\prime}$-aggacagataaaggtgatcc- $3^{\prime}$ and 5 '-agatactggactgggatcaa- $3^{\prime}$.

\section{Statistical analyses}

Data are expressed as mean \pm Standard Error of the Mean (SEM) and analyzed using GraphPad Prism-7 software (La Jolla, California, USA). Data followed normal distribution as evidenced by the Shapiro-Wilks normality test with the hypothesis for normality rejected at a $p$ value less or equal to 0.05 . Data were analyzed using Student's $t$ test, one-way or two-way analysis of variance (ANOVA) when relevant and as stated for each experiment. Tukey's or Fisher's LSD post-hoc multiple comparisons were applied. Outliers were identified using the Grubbs statistical test with alpha at 0.05 . For all analyses, a $p$ value $<0.05$ was considered significant.

\section{Results}

\section{Shank3+/ $\Delta C$ and Shank3 $\Delta C / \Delta C$ mice show impairments} in social novelty preference

Social preference and motivation in mice have strong face validity to simple social approach behaviors in humans, which are frequently impaired in ASD [32]. We have used here a standardized 3-CT procedure, as previously described [28, 29], and evaluated social preference and novelty. Surprisingly, we observed social preferences with all genotypes (Males: One-way ANOVA, $[\mathrm{F}(5,96)=23.69$, $p<0.0001]$; Females: One-way ANOVA, $[\mathrm{F}(5,76)=8.852$, $p<0.0001]$ ) and in both males (Tukey's post-hoc test: WT, $p<0.0001$; Shank3+/ $\Delta$ C, $p<0.0001$; Shank3 $\Delta \mathrm{C} /$ $\Delta \mathrm{C}, p<0.0001$ ) and females (Tukey's post-hoc test: WT, $p=0.026$; Shank3 $+/ \Delta C, p=0.0039 ;$ Shank3 $\Delta C / \Delta C$, $p=0.023$ ) (Fig. 1b, d). Indeed, mice from all genotypes and sex spent more time around the cage that contained another mouse than around an empty cage (phase 2). Preference for social novelty is defined as a significant propensity to spend more time with a new mouse than with a familiar mouse. When a novel mouse was then introduced in the opposite chamber (phase 3), only WT mice of both sexes showed social preference to the novel mouse (Males: One-way ANOVA, $[\mathrm{F}(5,94)=7.729$, $p<0.0001]$; Females: One-way ANOVA, $[\mathrm{F}(5,78)=10.21$, $p<0.0001]$ ). Tukey's post-hoc test revealed a significant increase (males: $+94.65 \%$; females: $+146.70 \%$ ) in the time spent within the cage area of the novel mouse only in the WT group of males $(p=0.0016)$ and females $(p<0.0001)$ but not in either the Shank $3+/ \Delta \mathrm{C}$ or the $\Delta \mathrm{C} /$ $\Delta \mathrm{C}$ groups of males or females (Fig. 1f, $\mathrm{h}$ ).

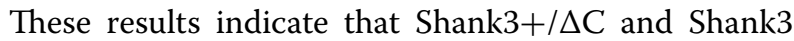
$\Delta C / \Delta C$ males and females show social preference and motivation but have impaired preference for social novelty as they show no preference for a newly introduced mouse compared to a mouse with which they have previously interacted.

\section{Shank3 $\Delta C / \Delta C$ mice show increased self-grooming frequency}

Self-grooming is an innate behavior in rodents and its alteration is used as an indication of compulsive and repetitive behavior [33]. Motor stereotypies, repetitive and uncontrollable motor behaviors are among the core symptoms of ASD. Most Shank3 mouse models were shown to display increased self-grooming although with conflicting results in relation to the genotype and the sex of mice [17, 18, 21-24]. Here we have assessed grooming in a novel environment (a transparent cylinder) with home cage bedding (Fig. 2). We report that time spent grooming is not significantly different in relation with genotype in males (One-way ANOVA, $[\mathrm{F}(2,36)=2.653$, $p=0.0842]$ ) and females (One-way ANOVA, $[\mathrm{F}(2,34)=0.232, p=0.79]$ ) (Fig. 2a, b). However, there was a significant effect in the number of grooming episodes in relation with genotype (Males: One-way ANOVA, $[\mathrm{F}(2,36)=14.71, p<0.0001]$; Females: One-way ANOVA, $[\mathrm{F}(2,34)=7.951, p=0.001])$. Indeed, Tukey's post-hoc analysis showed that the number of grooming episodes increased in both the Shank $3 \mathrm{C} / \Delta \mathrm{C}$ groups of males and female mice $(p<0.0001$ and $p=0.03$, respectively) (Fig. 2c, d). These results are in line with previous reports in several mouse models bearing a Shank3 mutation indicating increased grooming in these mouse models as a key behavioral feature.

\section{Shank3 $\Delta C / \Delta C$ mice show motor coordination deficits}

Motor coordination deficits were found in ASD patients but are not used in the diagnosis criteria [34]. Motor coordination can be explored using the challenging beam test, usually performed in animal models of pathologies affecting motor behavior such as Parkinson's disease [35]. We have recently implemented and validated this procedure in two environmental mouse models of ASD [28, 29]. Here, we report that Shank3 $\Delta \mathrm{C} / \Delta \mathrm{C}$ mice display 


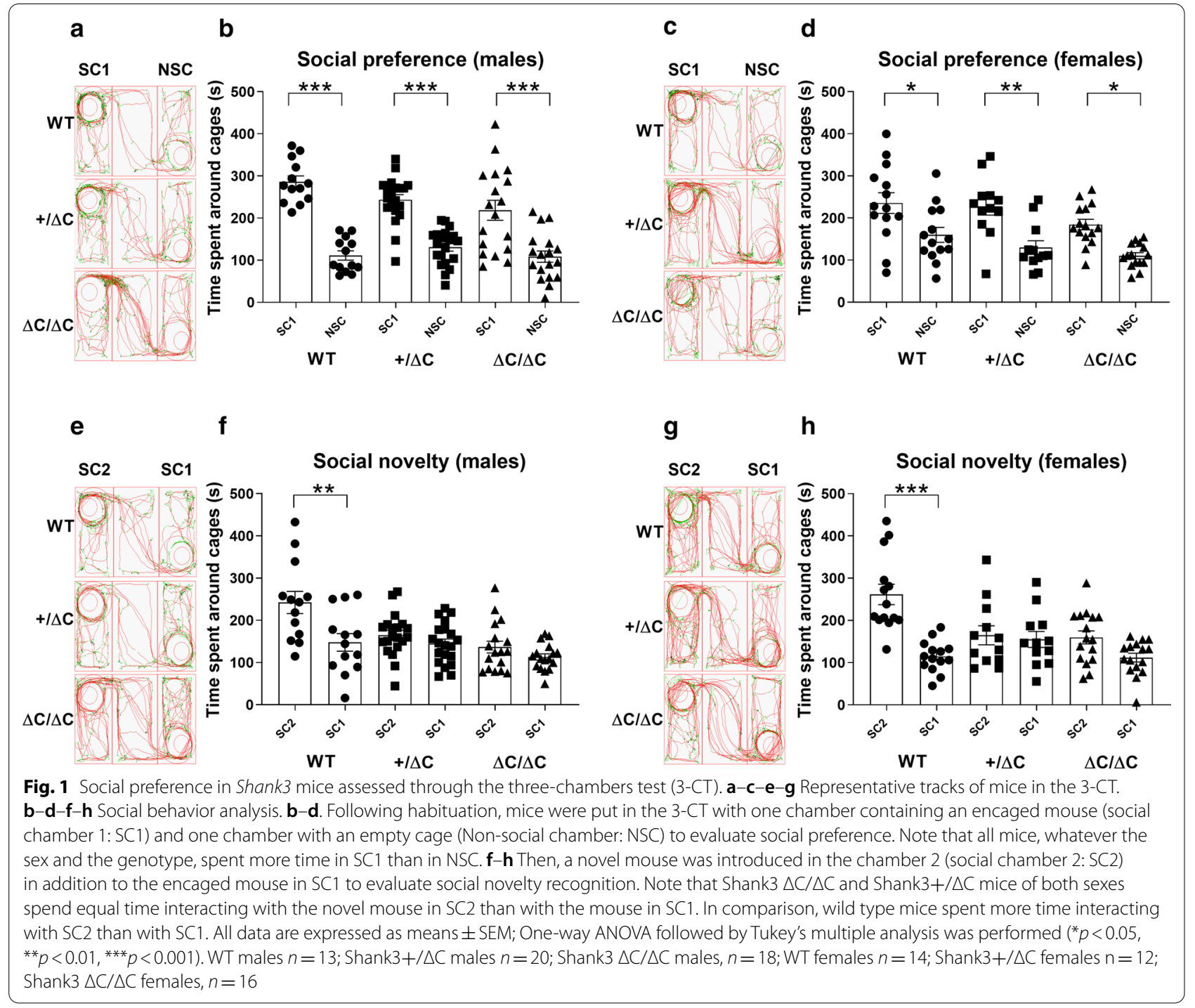

mild motor coordination deficits (Fig. 3). Indeed, there was a significant effect of genotype (One-way ANOVA, $[\mathrm{F}(2,40)=10.07, p=0.001])$ in the number of mistakes while traversing the last, and thus the narrowest, section of the beam in the Shank3 $\Delta \mathrm{C} / \Delta \mathrm{C}$ female group (Tukey's post-hoc analysis, $p=0.0008$ ) (Fig. 3b). In male Shank3 $\Delta \mathrm{C} / \Delta \mathrm{C}$ mice, there was clearly a tendency towards motor deficits but that did not reach significance (One-way ANOVA, $[\mathrm{F}(2,41)=2.758, p=0.075)$ (Fig. 3a). Shank3+/ $\Delta C$ mice did not show any deficits, whatever the sex and the section of the beam.

\section{Shank3 $\Delta C / \Delta C$ mice show gait abnormalities}

Although gait disturbances and motor development delays have been constantly reported in ASD patients [36], they are still not included in the diagnosis criteria.
We have previously shown in the VPA and Poly IC ASD mouse models significant alterations in several gait parameters explored here (Figs. 4, 5).

We found that Shank3 $\Delta \mathrm{C} / \Delta \mathrm{C}$ mice display several gait abnormalities in greater number in males than in females. For example, in the male group these parameters include the following: (1) swing time (fore left paw: One-way ANOVA, $[\mathrm{F}(2,49)=12.48, p<0.0001]$ and fore right paw: One-way ANOVA, $[\mathrm{F}(2,49)=6.869, p=0.002])$. Tukey's multiple analysis showed that fore left paw was significantly decreased by $12.84 \%$ in Shank $3 \Delta \mathrm{C} / \Delta \mathrm{C}$ mice compared to wild type $(p=0.011)$ and the fore right paw was significantly decreased by $11.23 \%(p=0.036)$ (Fig. $4 \mathrm{c})$; (2) stance time was significantly affected in Shank3 $\Delta \mathrm{C}$ / $\Delta \mathrm{C}$ mice for the fore right, hind left and hind right paws whereas only a trend towards a decrease was observed for the fore left paw as revealed by post-hoc analysis. 


\section{a}

Males

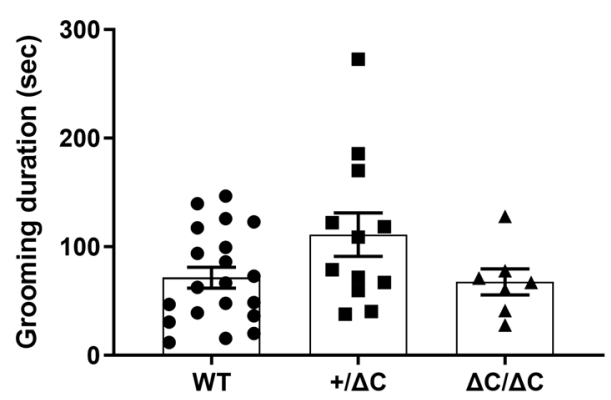

c

Males

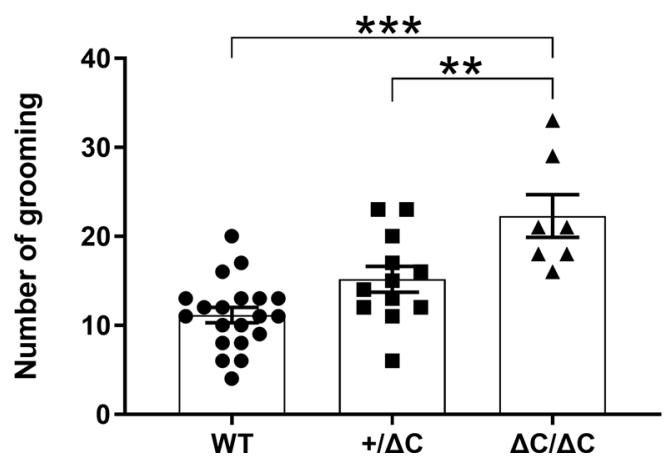

b

Females

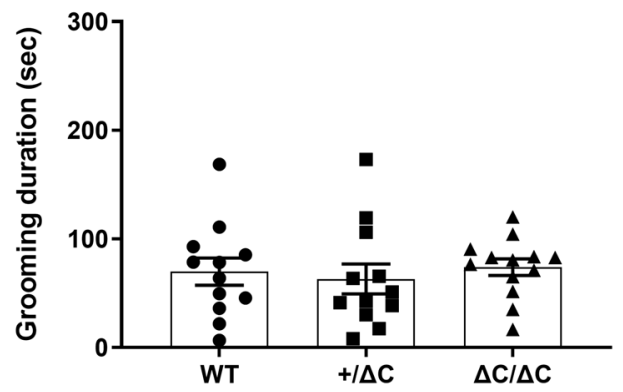

d

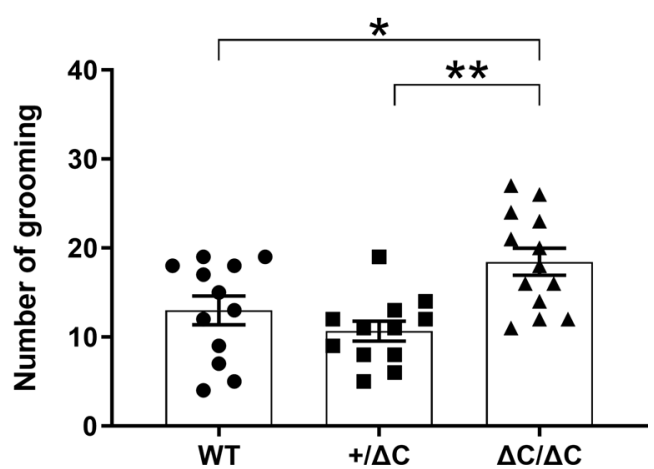

Fig. 2 Stereotyped behavior in Shank3 mice. a-d Grooming time and frequency in Shank3 mice. Mice were placed in a clean cylinder and videotaped. a-c There was no difference in the time spent grooming within all groups of mice. $\mathbf{b}-\mathbf{d}$ However, compared to WT, grooming frequency was increased in Shank3 $\Delta C / \Delta C$ and Shank3+/ $\Delta C$ males. Only Shank3 $\Delta C / \Delta C$ females showed increased grooming compared to WT and Shank3+/ $\triangle \mathrm{C}$ (B). All data are expressed as means \pm SEM. One-way ANOVA followed by Tukey's multiple analysis was performed ${ }^{*} p<0.05$, ${ }^{* *} p<0.01$, $\left.{ }^{* * *} p<0.001\right)$ WT males $n=20$; Shank3+/ $\Delta \mathrm{C}$ males $n=12$; Shank3 $\Delta \mathrm{C} / \Delta \mathrm{C}$ males, $n=7$; WT females $n=12$; Shank3+/ $\Delta \mathrm{C}$ females $n=12$; Shank3 $\Delta \mathrm{C} /$ $\triangle \mathrm{C}$ females, $n=13$

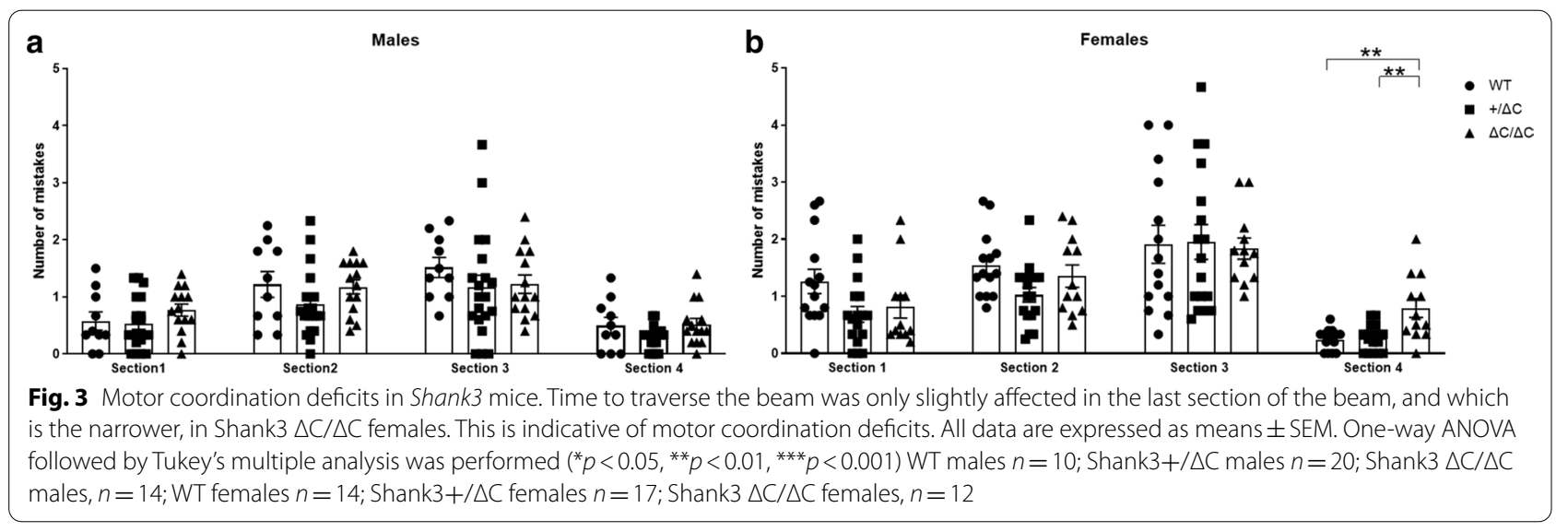

Tukey's multiple analysis showed a significant decrease of the stance time by $26.18 \%$ for Shank $3 \mathrm{C} / \Delta \mathrm{C}$ mice hind left paw $[\mathrm{F}(2,49)=9.003, p>0.01]$ (Fig. $4 \mathrm{~b}$ ); (3) stride frequency was also affected (One-way ANOVA followed by Tukey's multiple analysis (WT vs Shank3 $\Delta \mathrm{C} / \Delta \mathrm{C}$ );
Fore left paw: $[\mathrm{F}(2,49)=9.431, p=0.02]$, fore right paw: $[\mathrm{F}(2,49)=9.253, p=0.02]$, hind left paw: $[\mathrm{F}(2,49)=8.265$, $p=0.03]$ and hind right paw: $[\mathrm{F}(2,49)=8.675, p=0.03])$ (Fig. 4a); (4) left pair gap (One-way ANOVA followed by Tukey's multiple analysis (WT vs Shank3 $\Delta \mathrm{C} / \Delta \mathrm{C}$ ): 

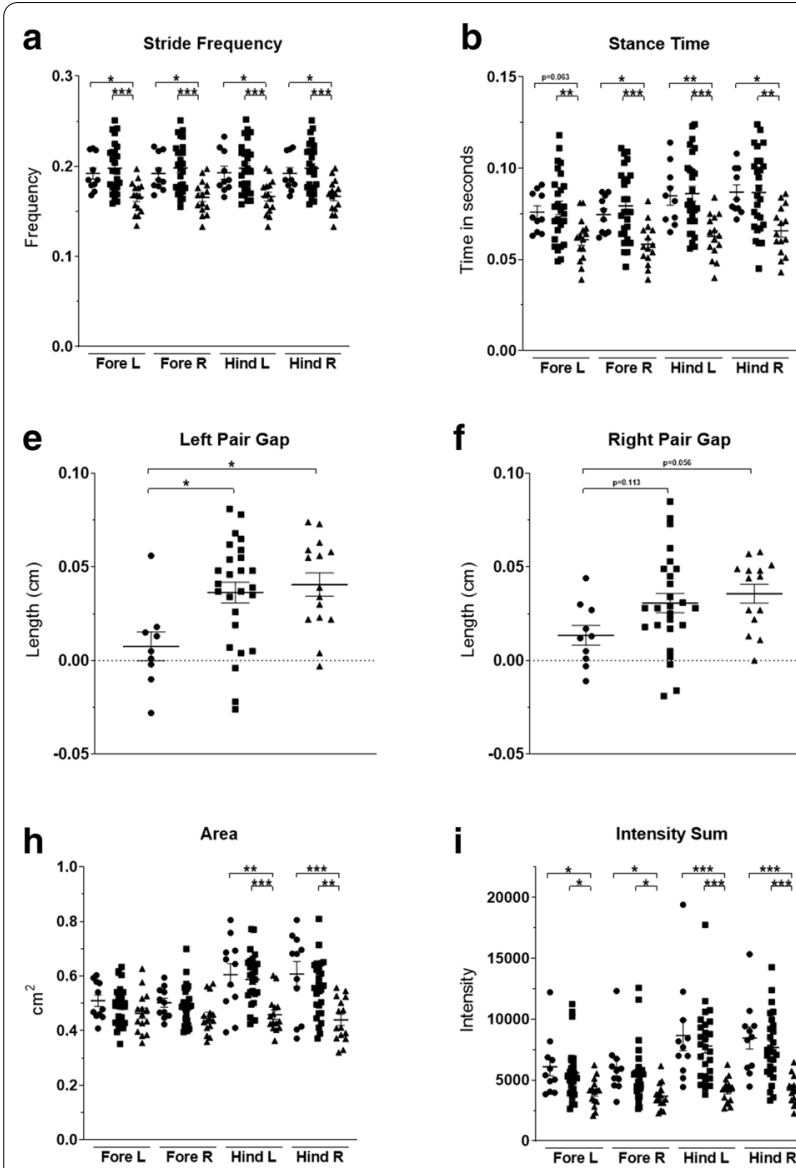
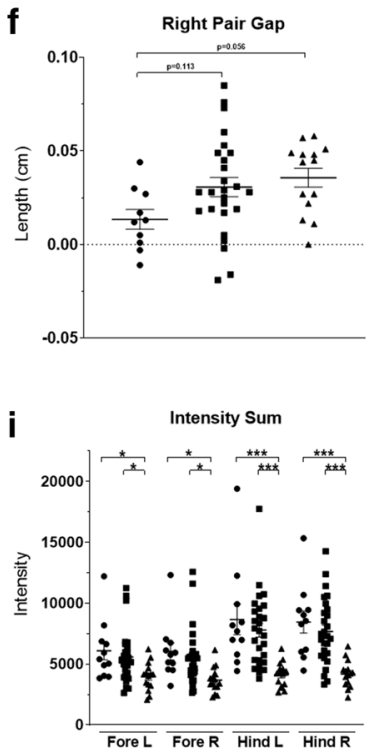
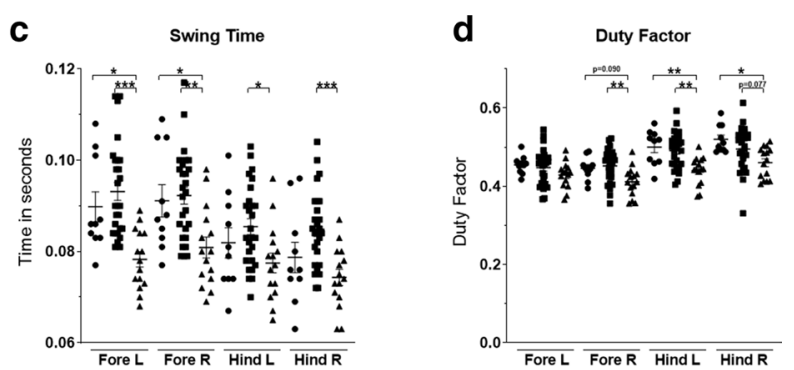

g

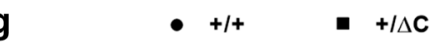

$\Delta \mathbf{C} / \Delta \mathbf{C}$
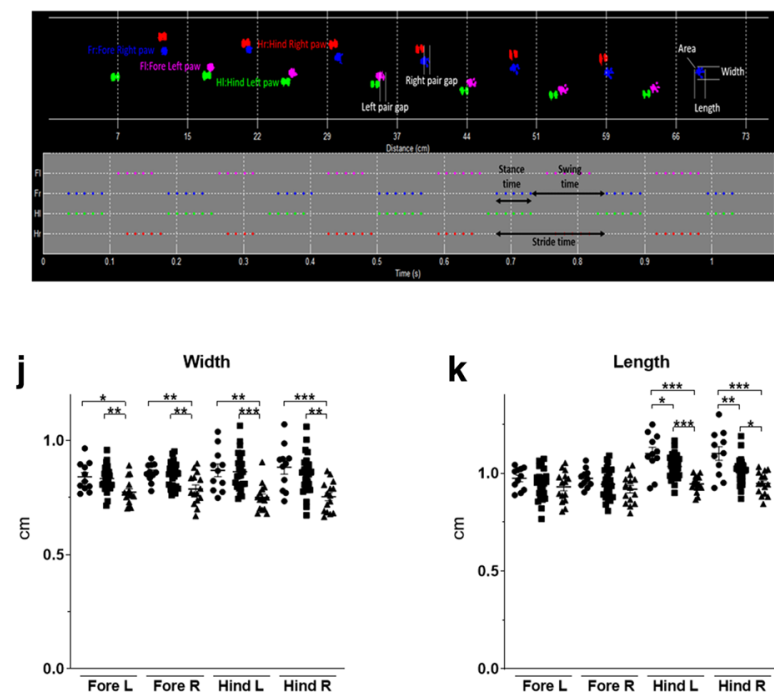

Fig. 4 Gait analysis in Shank3 males. Gait was analyzed during spontaneous walk using an automated gait analysis system (Viewpoint, France). Ten parameters were analyzed: a stride frequency, $\mathbf{b}$ stance time, $\mathbf{c}$ swing time, $\mathbf{d}$ duty factor, $\mathbf{e}, \mathbf{f}$ pair gap, $\mathbf{h}$ area, $\mathbf{i}$ intensity sum, $\mathbf{j}$ width, $\mathbf{k}$ length and $\mathbf{g}$ representative spatio-temporal gait analysis. All data are expressed as means \pm SEM. One way ANOVA followed by Tukey's multiple analysis was performed. $\left.{ }^{*} p<0.05,{ }^{* *} p<0.01,{ }^{* * *} p<0.001\right)$ WT males $n=11$; Shank3+/ $\Delta \mathrm{C}$ males $n=27$; Shank3 $\Delta C / \Delta C$ males, $n=15$

$([\mathrm{F}(2,47)=5.026, p=0.012])$ (Fig. $4 \mathrm{e}, \mathrm{f})$ and also area (Fig. 4h), width (Fig. 4j) and length (Fig. 4k) of the footsteps. Duty factor, which is the ratio of the limb stance time and limb stride time, was decreased only in Shank3 $\Delta \mathrm{C} / \Delta \mathrm{C}$ males (One-way ANOVA followed by Tukey's multiple analysis when applicable: Fore left paw: $[\mathrm{F}(2,49)=1.62, p=0.21]$. Fore right paw: $[\mathrm{F}(2,49)=5.372$, $p=0.1]$, hind left paw: $[\mathrm{F}(2,49)=8.365, p=0.01]$ and hind right paw: $[\mathrm{F}(2,49)=4.894, p=0.011]$. Intensity sum, defined as the sum of the work exerted through body movement and the resting, was decreased in both male and female Shank3 $\Delta \mathrm{C} / \Delta \mathrm{C}$ compared to wild type (One-way ANOVA followed by Tukey's multiple analysis: $([\mathrm{F}(2,50)=4.423, p=0.027]$ and $[\mathrm{F}(2,41)=6.165$, $p=0.003$ ], respectively) (Figs. 4i, 5h).

Similar alterations were also observed in the Shank3 $\Delta \mathrm{C} / \Delta \mathrm{C}$ female group but implicating less gait parameters than in males. For instance, Tukey's multiple analysis showed a significant decrease of the swing time by $19.71 \%$ for Shank3 $\Delta \mathrm{C} / \Delta \mathrm{C}$ mice fore left paw $[\mathrm{F}(2,41)=15.25, p<0.0001]$ and by for $20.79 \%$ the fore left paw $[\mathrm{F}(2,41)=15.01, p<0.0001]$. In addition, one-way ANOVA followed by Tukey's multiple analysis showed that swing time fore left paw $[\mathrm{F}(2,41)=15.25, p=0.004]$ and swing time fore right paw $[\mathrm{F}(2,41)=15.01, \quad p=0.016]$ were significantly reduced in female Shank3+/ $\Delta \mathrm{C}$ mice compared to $\mathrm{WT}$ (Fig. 5c). Stance time was also significantly affected in Shank3 $\Delta \mathrm{C} / \Delta \mathrm{C}$ and Shank3+/ $\Delta \mathrm{C}$ females. For example, One-way ANOVA followed by Tukey's multiple analysis showed the following differences between WT and Shank3 $\Delta \mathrm{C} / \Delta \mathrm{C}$ in fore left paw $[\mathrm{F}(2,41)=6.908$, $p=0.002]$, fore right paw $[\mathrm{F}(2,41)=6.797, p=0.002]$, fore left paw $[\mathrm{F}(2,41)=6.908, p=0.05]$ and fore right paw $[\mathrm{F}(2,41)=6.8, p<0.05]$ ) (Fig. $5 \mathrm{~b})$. For stride frequency, a significant decrease was observed for the fore and hind paws of Shank3 $\Delta \mathrm{C} / \Delta \mathrm{C}$ females compared to WT: fore left paw $[\mathrm{F}(2,41)=10.29, p=0.0001]$, 


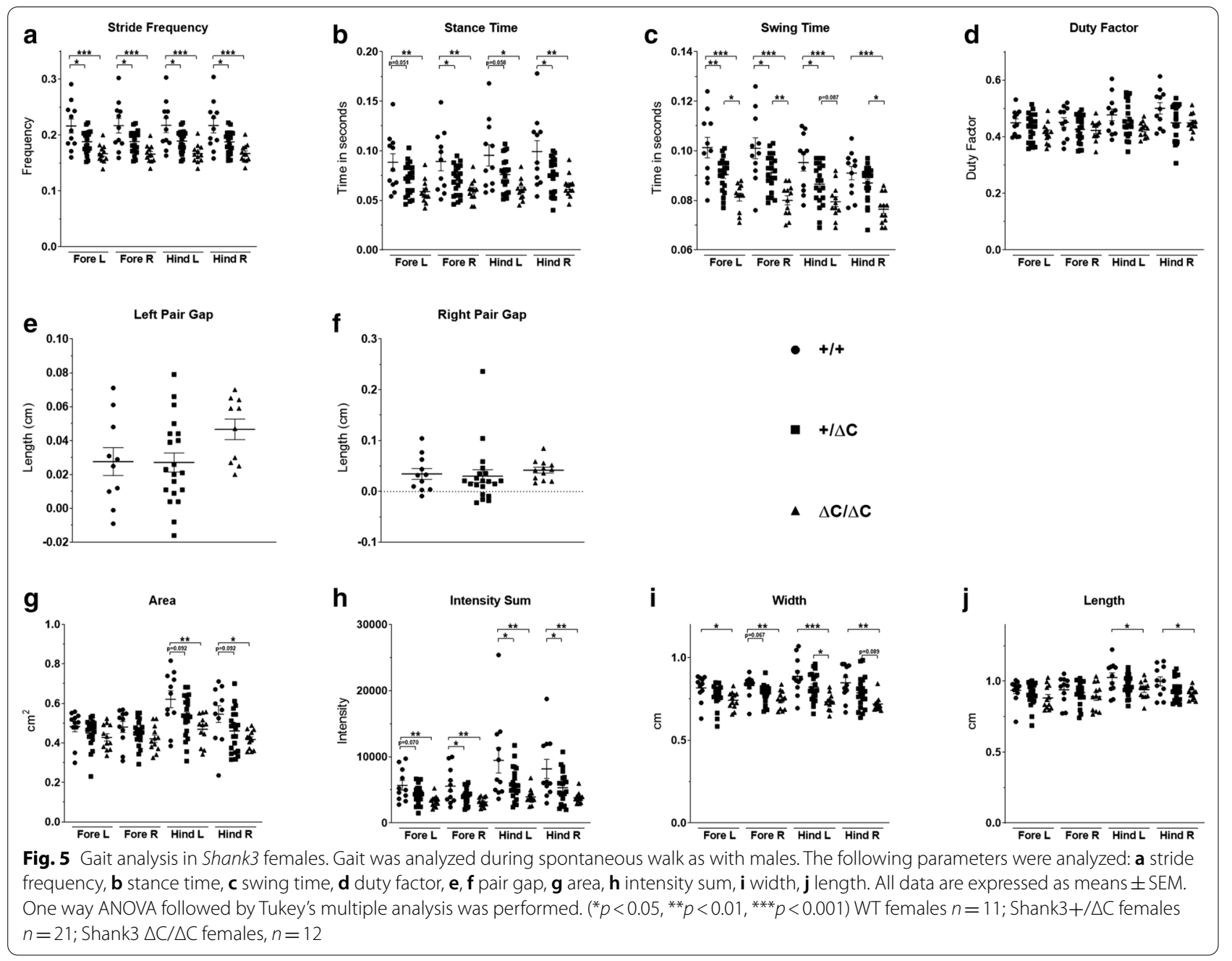

fore right paw $[\mathrm{F}(2,41)=10.35, p=0.0001]$, hind left paw $[\mathrm{F}(2,41)=10.55, p=0.0001]$ and hind right paw $[\mathrm{F}(2,41)=10.09, p=0.001])$. There were also differences in this parameter in Shank $3+/ \Delta \mathrm{C}$ females compared to WT: Fore left paw $[\mathrm{F}(2,41)=10.29, p=0.017]$, fore right paw $[\mathrm{F}(2,41)=10.35, \quad p=0.018]$, hind left paw $[F(2,41)=10.55, p=0.018]$ and hind right paw $[\mathrm{F}(2,41)=10.09, p=0.015]$ ) (Fig. 5a). Duty factor was not affected in Shank3 $\Delta \mathrm{C} / \Delta \mathrm{C}$ females compared to WT: Fore left paw $[\mathrm{F}(2,41)=1.861, p=0.17]$, fore right paw $[\mathrm{F}(2,41)=1.277, p=0.29]$, hind left paw $[\mathrm{F}(2,41)=2.524, p=0.09]$ and hind right paw $[\mathrm{F}(2,41)=3.206, p=0.051])$ (Fig. $5 \mathrm{~d}$ ).

Taken together, gait analysis indicates major abnormalities mainly in Shank3 $\Delta \mathrm{C} / \Delta \mathrm{C}$ mice, with more parameters encountered in males than in females. These abnormalities are often of spatio-temporal nature rather than anatomical [37].

\section{Male Shank3 $\Delta C / \Delta C$ mice show decreased Purkinje cell number}

We aimed at determining the effect of Shank3 mutation on cell numbers in the Crus I and Crus II cerebellar subregions that are known to play a major role in movement regulation, exploratory behavior, stereotyped and repetitive behaviors [38] but also in social interactions [39]. Several clinical studies in ASD [40,41] and explorations in animal models, including our own [28, 29, 42], have consistently shown a decrease in the number of these neurons in the cerebellum and mainly within the Crus I and/or Crus II sub-regions.

Here, we report that the Shank3 mutation resulted in a decreased number of PC in Crus I in both males and females (Fig. 6). Indeed, two-way ANOVA analysis showed a clear genotype (Two-way ANOVA, $[\mathrm{F}(2,44)=5.92, p=0.0053]$ ) and sex effect (Two-way ANOVA genotype $x$ sex interaction, $[F(2,44)=3.741$, 


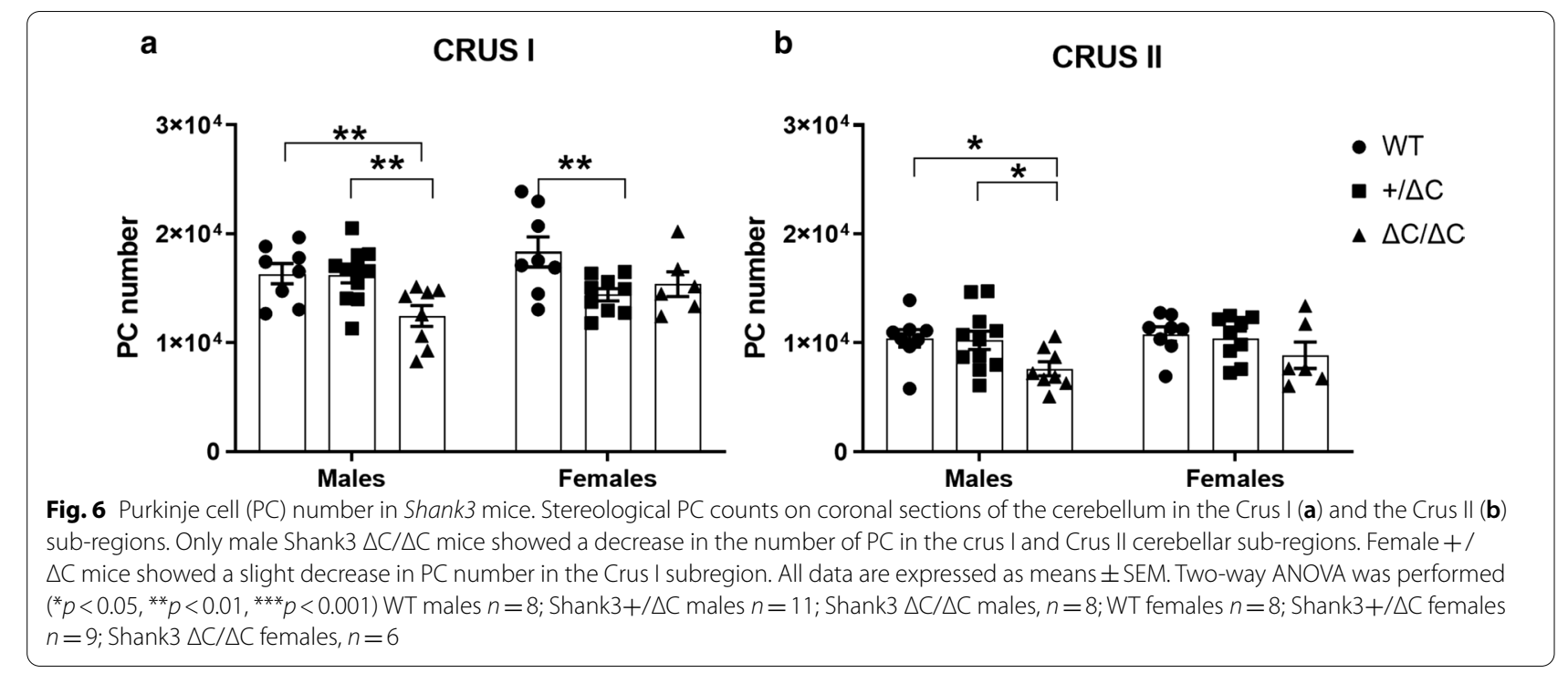

b CRUS II

$p=0.032])$. Fisher's LSD post-hoc analysis further indicated that the Shank3 $\Delta \mathrm{C} / \Delta \mathrm{C}$ male group had a lower number of PC than wild type in both the Crus I and Crus II cerebellar area $(p=0.0066$ and $p=0.0206$, respectively) (Fig. 6a, b). Females Shank3 $+/ \Delta C$ mice showed a mild but significant decrease in $\mathrm{PC}$ number in the Crus I subregion (Two-way ANOVA followed by Fisher's LSD post-hoc analysis, $[\mathrm{F}(2,44)=5.92, p=0.005]$ ) (Fig. 6a). In conclusion, the lower number of $\mathrm{PC}$ affects mainly Shank3 $\Delta \mathrm{C} / \Delta \mathrm{C}$ male mice as also reported in the VPA and poly IC mouse models.

\section{Male Shank3 mice show decreased cerebellar mGluR5 levels}

The Shank3 C-terminal region (exon 21-22), which is mutated in these mice, contains binding sites for mGluR5 and plays a crucial role in the synaptic targeting and postsynaptic assembly of Shank3 scaffolding complex [43-45]. We thus explored the cerebellar levels of this receptor and associated scaffolding proteins, along with a set of other glutamate receptors and postsynaptic proteins (Fig. 7). Surprisingly, only mGluR5 levels were dramatically decreased and this was observed only in Shank $3+/ \Delta \mathrm{C}$ and Shank3 $\Delta \mathrm{C} /$ $\Delta C$ males. Indeed, ANOVA analysis showed a genotype effect (One-way ANOVA, [F $(2,16)=6.368$, p0.0092]) and Tukey's multiple analysis revealed decreased levels of mGluR5 in males Shank3+/ $\Delta \mathrm{C}$ and Shank3 $\Delta \mathrm{C} /$ $\Delta \mathrm{C}$ mice compared to WT $(p=0.022$ and $p=0.009$, respectively). This decrease was dramatic in magnitude (down to $-71.32 \%$ ) in male Shank3 $\Delta \mathrm{C} / \Delta \mathrm{C}$ mice (Fig. 7a). In order to determine whether this decrease was specific to the Shank3 mutation, we also evaluated levels of mGluR5, and NR1, NR2A and NR2B glutamate receptors' subunits in a mouse model of prenatal VPA injection as described [28], and found no modifications in these levels $(\mathrm{t}(8)=0.8569$, $p=0.4164$ for mGluR5, $\mathrm{t}(8)=0.8427, p=0.4239$ for NR1, $\mathrm{t}(8)=1.574, p=0.1540$ for NR2A, $\mathrm{t}(8)=1.31$, $p=0.2266$ for NR2B). We further evaluated mGluR5 mRNA levels by RT-PCRq in order to determine whether the decrease in mGluR5 protein levels was due to transcriptional or translational regulations and found no alterations in the corresponding mRNA levels. Males: One-way ANOVA, $[\mathrm{F}(2,20)=1.748, p=0.1996])$ and females: One-way ANOVA, $[\mathrm{F}(2,19)=1.985$, $p=0.1648])$.

\section{Discussion}

This study aimed at investigating several behavioral, cellular, and molecular outcomes related to ASD in Shank3 $+/ \Delta C$ and Shank3 $\Delta C / \Delta C$ male and female mice with a mutation that is also observed in human conditions.

The Shank3 gene encodes a master scaffolding protein in the postsynaptic density where it interacts with multiple key synaptic components, mainly implicating the glutamate receptor clusters, along with the cytoskeleton and signal transduction cascades [10, 26, 43, 44, 46]. The gene is located on chromosome $22 \mathrm{q} 13.3$ in humans and was first implicated in ASD in the 22q13.3 microdeletion syndrome, also known as Phelan-McDermid Syndrome [13]. Haploinsufficiency of the Shank3 gene accounts for $0.5-2.0 \%$ of ASD and intellectual disability cases [16, 47]. Human genetic studies of ASD have found that the 
(See figure on next page.)

Fig. 7 Brain levels in PSD proteins and mRNA in ASD mouse models. a-c Expression profile of Shank3 and associated postsynaptic scaffolding proteins in males and females Shank3 mice within the cerebellum by immunoblot analysis. b-d Representative figures of the western blot. Note

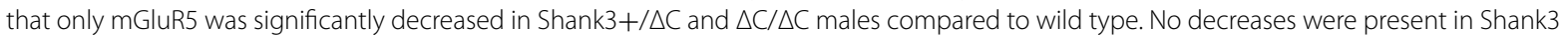

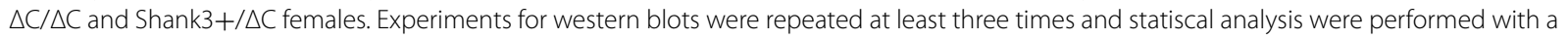
one-way ANOVA followed by Tukey'smultiple analysis $\left({ }^{*} p<0.05,{ }^{* *} p<0.01,{ }^{* * *} p<0.001\right)$ WT males $n=4$; Shank3+/ $\Delta \mathrm{C}$ males $n=8$; Shank3 $\Delta \mathrm{C} / \Delta \mathrm{C}$ males, $n=8 ;$ WT females $n=5$; Shank3+/ $\Delta C$ females $n=8$; Shank3 $\Delta C / \Delta C$ females, $n=9$. e No difference in the protein levels of several glutamate receptors was found in the male cerebellum of VPA ASD mouse model whatever the prenatal treatment (Saline, $n=5 ; \mathrm{VPA}, n=5$, Student's $t$ test, $p>0.05)$. $\mathbf{f}$ No difference in the mGluR5 mRNA levels was found in the cerebellum whatever the genotype or sex (wild type males $(n=7)$, Shank3+/ $\Delta C$ males $(n=8)$, Shank3 $\Delta C / \Delta C$ males $(n=8)$, wild type females $(n=7)$, Shank3+/ $\Delta C$ females $(n=8)$, Shank3 $\Delta C / \Delta C$ females $(n=8)$, One-way ANOVA, $p>0.05)$. All data are expressed as means \pm SEM

C-terminal region (exon 21) of Shank3 harbors several mutations [16]. This region encodes binding sites for actin/Cortactin and mGluR5/Homer and plays a crucial role in the synaptic targeting and postsynaptic assembly of Shank3 scaffolding proteins [48]. A dozen different genetically alerted mice with various Shank3 point mutations or deletions of a given exon have been constructed [17-19, 24, 26, 42, 49]. These mice show variable outcomes at the behavioral, cellular, and molecular levels.

We have set up our behavioral, cellular, and molecular analysis in a Shank3 mouse model [17] based on our previous and recently reported findings in two different environmental mouse models of ASD [28, 29]. These models were obtained following prenatal injection of either VPA or poly IC and recapitulate several ASD symptoms, although at different degrees and magnitude, with a clear sexual dimorphism.

Here, we show that a Shank3 mutation affects mostly male homozygote mice in several social and motor behavioral parameters. This is accompanied by a significant reduction in cerebellar PC and specific decreased levels of mGluR5 proteins. We first investigated social preference parameters, as they constitute one of the hallmarks of ASD [50]. We report that Shank3+/ $\Delta \mathrm{C}$ and Shank3 $\Delta C / \Delta C$ males and females both have normal social preference and motivation but show impairments in social novelty preference. Of interest is the fact that ASD patients are reported to avoid unfamiliar social partners and display diminished interest in novelty [50]. Indeed, ASD patients tend to avoid social contacts with a new individual compared to someone familiar [51].

Self-grooming is a core behavior for mice that spend about $40 \%$ of their waking time performing it. It is aimed to maintain physiological stasis and comfort and thus tends to increase under stressful situations and in pathological conditions implicating motor brain centers as reported in clinical and animal models of ASD [33]. Here, we replicated findings in these animal models showing increased grooming, reflective of stereotyped repeated behavior. We further show that this increased grooming affects both Shank3 $\Delta \mathrm{C} / \Delta \mathrm{C}$ males and females.
In the initial paper using this line of mice [17], authors have investigated a wide range of behavioral parameters including motor-coordination deficits, grooming and novelty avoidance, but only in homozygote mice. Of interest is the observation that homozygote mice showed social preference in the phase 2 of the 3-CT but no preference for social novelty (phase 3 ), a finding that we replicated here both in males and females. In the report by Duffney et al., (2015), Shank3 $+/ \Delta C$ did show social preference in phase 2 trial but that was of a lesser magnitude than in wild type animals [18]. Qin et al. [19] used the 3-CT with only two phases and showed no social pref-

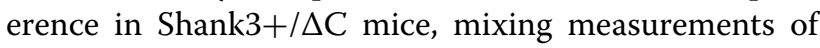
"investigating behavior" and time spent in the area surrounding the cup with the social cue. Using a similar mutation leading to a premature stop codon in exon 21 of Shank3, Speed et al. [24] found no social interaction deficits in both heterozygote or homozygote mouse mutants. Also in this paper, homozygote mice, but not heterozygotes, showed deficits in hippocampus-dependent spatial learning, impaired motor coordination, altered response to novelty, and sensory processing deficits. Jaramillo et al. [22] used a different approach to generate Shank3 mutant mice with a loss of the two higher molecular weight isoforms by disrupting the PDZ domain with a transcriptional stop cassette prior to exon 13. Homozygote mice with this mutation, but not heterozygotes, displayed a preference for the social target over the inanimate object (phase 2), a finding that we replicated here. In the phase 3 of the 3-CT, neither heterozygote nor homozygote mice displayed preference to social novelty as also we show here for homozygote mice. In addition, interaction time and approach were altered only in homozygote animals, in line with our findings of altered social behavior only in homozygotes. In the grooming behavior, both heterozygotes and homozygotes displayed increased time spent grooming compared to wild type, but only homozygotes showed increased grooming bouts, a finding that we also replicate in the Shank3 mouse models that we used. Although apparently conflicting, collectively these results show alterations in grooming and social behavior in Shank3 mutant mice, which are often present only in 


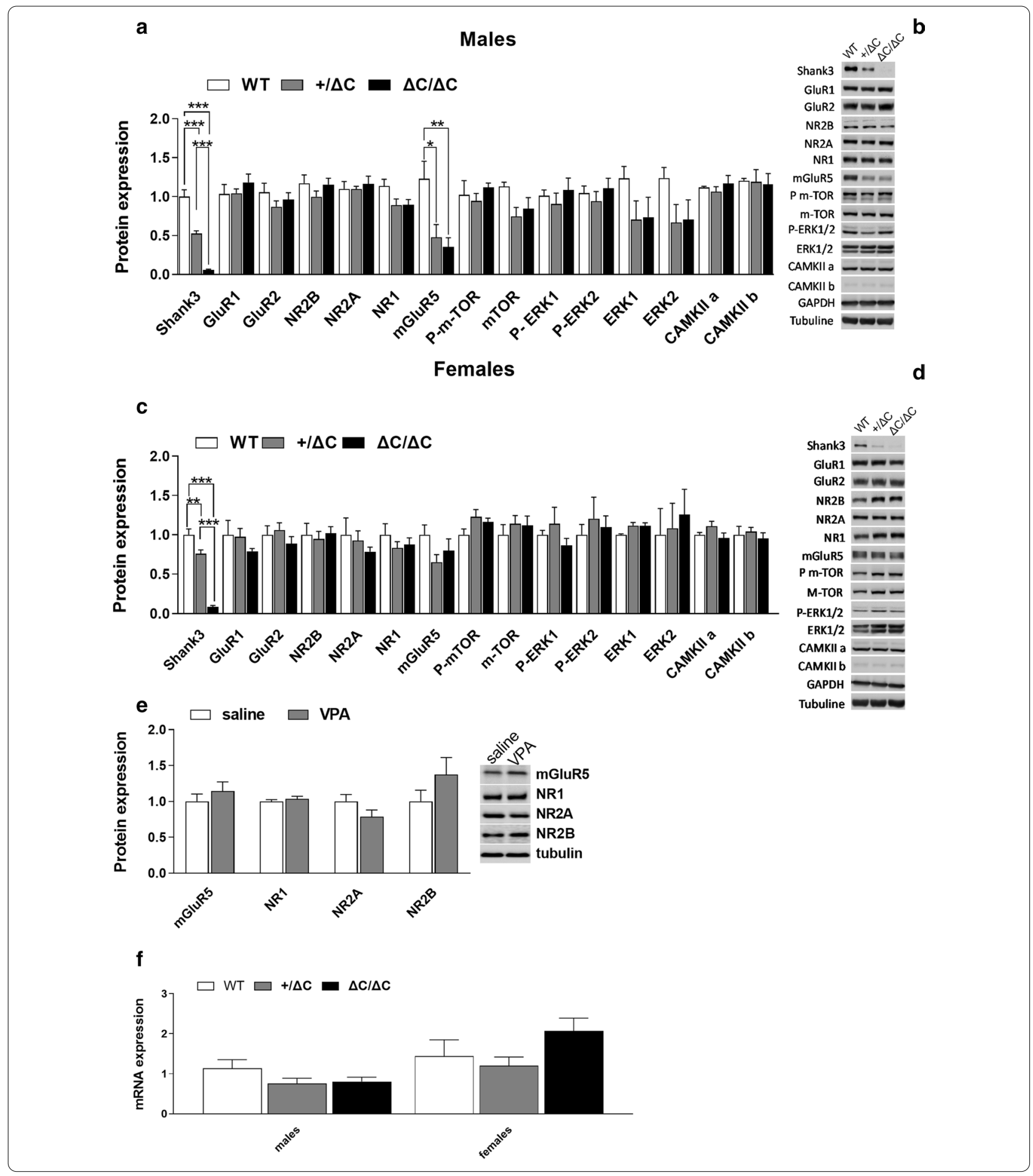

homozygotes or at least with a much higher degree than in heterozygote mice.

Several reports in ASD described impairments in visiomotor and manual dexterity tasks, limb coordination during tasks requiring balance, agility, and speed, as well as in gait and ataxia [52]. Furthermore, motor impairments may be amongst the earliest signs of some forms of ASD and their assessment might help the early and quantitative diagnosis of the pathology and the identification of dysfunctional brain regions and circuits in 
ASD [53]. Here, we found only mild motor coordination impairments in this mouse model. These impairments were revealed only when the task required significant challenge (a very narrow beam with a grid mech above it). This is in line with our findings with a Poly IC environmental model where no deficiencies were observed in this task [29].

One of the most robust and consistent findings in our previous studies and here are anomalies in gait. Early studies in ASD patients have revealed irregular gait [54]. Quantitative measures indicated increased variability and irregularity in gait suggestive of cerebellar, rather than basal ganglia, involvement. Later studies reported increased missteps, increased step width, and higher ataxia ratios similar to what is found in patients with cerebellar lesions [55]. In fact, several spatiotemporal gait parameters of children with ASD were similar to those of patients with cerebellar ataxia [56]. Of interest is the fact that abnormal gait patterns seem to be correlated with the severity of social impairments in both humans [57] and ASD animal models [28]. Here, we have used an automated rodent quantitative gait analysis system with optical touch sensors, which records and tracks rodents' footprints as they move freely in a walkway. This allowed qualitative and quantitative readout of footprint pattern and contacts, highlighting gait abnormalities. As nearly all gait parameters are correlated, a collection of these parameters is needed to determine the potential alterations' nature. Gait is made up of strides that comprise a stance phase with the foot in contact with the ground and a swing phase with the foot off the ground. Fundamental descriptors of gait can be divided into two main sections: (1) spatial patterns that include stride length, step length, and step width and (2) temporal parameters including duty factor (limb stance time divided by stride time) and limb phase (the time between forelimb and hindlimb foot-strike on the same side divided by the stride time). We report here that several temporal parameters were altered and that these alterations were mainly found in Shank3 $\Delta C / \Delta C$ mice and to a wider extend in males. Interestingly, spatial patterns did not seem to be altered by the mutation (stride length did not differ between groups), indicating no major anatomical alterations in these mice. However, all temporal parameters measured were reduced in Shank3 $\Delta \mathrm{C} / \Delta \mathrm{C}$ mice (stance time, swing time, stride frequency, and duty factor). Along with these temporal deficiencies, there were also alterations of the way paws are applied to the surface in terms of surface contact and strength, and that were also reduced mainly in both males and females Shank3 $\Delta \mathrm{C} / \Delta \mathrm{C}$. Also of interest is the fact that more gait parameters were affected in males than in females. The temporal and surface alterations observed are probably not due to change in velocity as only females, but not males, Shank $3 \Delta \mathrm{C} / \Delta \mathrm{C}$ mice showed a mild increase (less than 20\%) in velocity; in addition, there was no change in the regularity of gait nor the stride length. Altogether, these gait elements argue against an anatomical alteration and a primary motor disorder implicating the basal ganglia. In contrast, they seem to point to a cerebellar dysfunction as they mainly affect movement coordination, a cerebellar function, which is in line with clinical findings (see for instance reference [56]).

Gait disturbances, and more generally behavioral abnormalities in neurodevelopmental disorders including ASD, are a consequence of underlying alterations in circuit maturation and function. Post-mortem and brain imaging studies have consistently identified the cerebellum as one of the most abnormal brain regions associated with ASD with a specific reduction of cerebellar PC [40, 41]. Here we show a decreased number of PC within the hemispheric part of lobule VII, within the in Crus I and Crus II subregions and only in Shank $3 \mathrm{C} / \Delta \mathrm{C}$ males. Females showed only a mild decrease in $\mathrm{PC}$ number in Shank3 $+/ \Delta C$. This is in line with VPA and Poly IC models showing also decreases of PC in these brain areas and that were more pronounced in males than in females. Cerebellar defects seem to be widespread in ASD mouse models. Using five different ASD mouse models, including the one used in this study, Kloth et al. [49] have shown major cerebellar associative sensory learning deficits with the eyeblink conditioning task, a task that relies on cerebellar plasticity. Further on, mice with a Tsc1 mutation specifically in cerebellar cells PC showed ASDrelated altered behavior that was rescued with rapamycin treatment targeting mTOR signaling further pointing to these cells as key players in ASD [42].

In this line, we investigated the levels of dozens of cerebellar proteins implicated in the cerebellar glutamatergic transmission and signal transduction. In accordance with previous findings in cortical or hippocampal areas, we did not detect any difference in the cerebellar expression level of several glutamatergic related proteins [18, $19,24]$. We further extend these findings and show here a dramatic decrease in the levels of cerebellar mGluR5 protein, and only in male Shank3 $\Delta \mathrm{C} / \Delta \mathrm{C}$, pointing to that receptor as the major target of Shank3 and perhaps even the major component underlying the observed behavioral deficits linked to this mutation. These decreased protein levels were probably due to post-translational regulation as we did not detect any alterations in the corresponding mRNA levels. Of interest is also the fact that such a decrease was not observed in the VPA environmental ASD mouse model. Shank3 is essential to mediating mGluR5 signaling by recruiting Homer1b/c to the postsynaptic density $[17,18,44]$. Pharmacological 
enhancement of mGluR5 activation in Shank3 knock-out mice, through the administering 3-Cyano- $N$-(1,3-diphenyl-1H-pyrazol-5-yl)benzamide, ameliorated functional and behavioral defects [58], suggesting that pharmaceutical treatments that increase mGluR5 activity may represent an interesting approach for treating ASD patients with a Shank3 mutations $[18,59,60]$. In this line, restoration of Shank3 expression in adult using a Shank3 conditional knock-in procedure in mice, rescued several ASD phenotypes through improvements in synaptic protein composition, spine density, and neural function [27]. This is of interest as it further emphasis the major role of Shank3 in postsynaptic function and indicates that this neurodevelopmental pathology may in fact be manageable at adult age in patients with Shank3 mutations.

Shank3 mutations in ASD patients are either point mutations in one copy of the Shank3 gene or haploinsufficiencies where a single functional Shank3 allele is insufficient to maintain a normal behavior $[14,61]$. Thus, one would have expected that Shank3 $+/ \Delta \mathrm{C}$ mice would show clear behavioral alterations relevant to ASD. In our hands however, Shank3+/ $\Delta \mathrm{C}$ mice showed deficiencies in the social novelty recognition task and did not show other behavioral or cellular dysfunction, despite over a $50 \%$ decrease in mGluR5 expression. This is in line with previous publications with this or similar mouse model $[17,24]$ but at odds with other previous reports exploring behavioral and cellular consequences only in males [18, 19].

Several studies utilizing Shank3 mutations or deletions do not report measurable changes in animal behavior. For instance, exons 4-9 of Shank3 (JAX 017890) show only mild ASD-related phenotype and have normal sociability and social novelty in the 3-chamber test [61]. Mutations targeting exons 4-7 only yielded mild behavioral phenotypes, while targeting exons 13-16 (JAX 017688) showed profound phenotypes such as impaired sociability and preference for social novelty, as well as reduced pair interaction, and profound self-grooming leading to skin lesions [62]. Targeting exon 11 induced prominent self-grooming and skin lesions [63], while targeting exon 21 of Shank3 (JAX 018398) results in normal sociability but impaired social novelty in the 3-chamber test [17], as observed in our study here.

\section{Limitations}

The construct validity of several, but not all, of the Shank3 mouse lines is strong as they tend to reproduce human mutations. However, several of these mouse models may have limited face validity, given that they sometimes fail to reproduce behavioral and cellular symptoms reported in ASD patients. Another element to take into consideration is the fact that each of these mutants targeted only a subset of Shank3's coding exons. Consequently mice only lacked a subset of Shank3 protein isoform, which may have differential function across brain regions, developmental time periods, or cell types [64]. Another limitation is the possibility that some Shank3 mutations lead only to subtle or limited forms and symptoms in the autism spectrum and that are difficult to detect in mice (such as intellectual disabilities).

\section{Conclusion}

Several major conclusions can be drawn from our study and several previous related findings: (1) the need to include females and heterozygote mice in separate groups in ASD animal models. (2) Even though Shank3 mutations have strong construct validity when produced in a way to mimic the genetic deletions and mutations observed in humans, there is a need to better evaluate Shank3 mouse models' face validity. For instance, in our hands and in previous reports $[17,24]$, Shank $3+/ \Delta C$ did not show major ASD-related behavioral deficits, contrary to the haploinsufficiency Shank3 deletions in humans. (3) Our findings, along with our previous reports in environmental mouse models of ASD, clearly point to gait disturbances as being key behavioral features in ASD, whatever the disease's etiology, with symptoms that are in line with clinical findings. This is of interest as gait investigations can be implemented early during the diagnosis procedures when ASD is suspected; they are also quantitative in an objective and reproducible manner. As such, gait needs to be considered as a credible new diagnostic criterion in ASD.

\section{Abbreviations}

SHANK: SH3 and multiple ankyrin repeat domains; ASD: Autism Spectrum Disorders; PC: Purkinje cells; ANOVA: Analysis of variance; mGluR5: Metabotropic glutamate receptor 5; NRXN: Neurexin; NLGN: Neuroligin; TSC1/2: Tuberous sclerosis 1/2; FMR1: Fragile Mental Retardation 1; VPA: Valproic acid; MIA: Maternal immune activation; 3-CT: Three-chambers test; PFA: Paraformaldehyde; SDS: Sodium dodecyl sulfate; TBST: Tris Buffer Solution Tween; P-mTOR: Phosphorylated mammalian target of rapamycin; mTOR: Mammalian target of rapamycin; ERK1/2: Extracellular signal regulated kinase; NR2A: N-Methyl-daspartate receptor subunit 2A; NR2B: N-Methyl-d-aspartate receptor subunit 2B; GluR1: a-Amino-3-hydroxy-5-methyl-4-isoxazolepropionic acid receptor subunit 1; GAPDH: D-Glycéraldéhyde-3-phosphate déshydrogénase; NR1: N-Methyl-d-aspartate receptor subunit 1; GluR2: a-Amino-3-hydroxy-5methyl-4-isoxazolepropionic acid receptor subunit 2.

\section{Acknowledgements}

We thank our laboratory's technical staff and the PREBIOS animal facility's staff (University of Poitiers-France). Special thanks to Dr Pierre-Olivier Fernagut for his precious advice and comments on the work performed and the manuscript.

\section{Authors' contributions}

EM and AM performed all behavior experiments, western blotting and histological studies; they performed all statistical analysis, constructed the figures and wrote the paper. MT performed some of the stereotyped behavior 
and genotyped mice. EB helped setting up, performing and supervising several behavior experiments. AB helped with the western blot studies and was in charge of interactions with the animal facility and ethical committee. MF helped with the histological studies and basic laboratory procedures. LG supervised the Shank3 colony, helped with the immunohistochemistry and discussed findings. MJ designed experiments, supervised the project, discussed findings, sought funding and wrote the manuscript. All authors read and approved the final manuscript.

\section{Funding}

This work was supported by grants from the Fondation pour la Recherche Médicale (FRM). EM was a recipient of a PRESTIGE funding from the EU (20171-044). AM is a recipient of a PhD fellowship from the French ministry. MT is a recipient of a PhD funding from the Inserm and the Nouvelle-Aquitaine Region, France. Several equipment used in this study were acquired with European Union's FEDER and the region of Nouvelle-Aquitaine funds. The University of Poitiers and INSERM provided infrastructural support. Funders had no role in study design, data collection and analysis, decision to publish the manuscript.

\section{Availability of data and materials}

Most of the data generated and analyzed during this study are included in this published article. All datasets used and/or analyzed during the current study are available from the corresponding author on reasonable request.

\section{Ethics approval and consent to participate}

Animal housing and experimental procedures were performed under the European Union directive (2010/63/EU) and validated by the regional ethical committee (Approval\# 2015020415093780).

\section{Consent for publication}

Not applicable.

\section{Competing interests}

The authors declare that they have no competing interests.

\section{Author details}

${ }^{1}$ Université de Poitiers, INSERM, Laboratoire de Neurosciences Expérimentales et Cliniques, 86073 Poitiers, France. ${ }^{2} \mathrm{CHU}$ de Poitiers, 86000 Poitiers, France.

Received: 16 October 2020 Accepted: 29 December 2020

Published online: 19 January 2021

\section{References}

1. Association AP. Diagnostic and statistical manual of mental disorders $\left(\right.$ DSM- $\left.5^{\circledR}\right)$. Philadelphia: American Psychiatric Pub; 2013

2. Loomes R, Hull L, Mandy WPL. What is the male-to-female ratio in autism spectrum disorder? A systematic review and meta-Analysis. J Am Acad Child Adolesc Psychiatry. 2017;56(6):466-74.

3. Baron-Cohen S, Knickmeyer RC, Belmonte MK. Sex differences in the brain: implications for explaining autism. Science. 2005;310(5749):819-23.

4. Auyeung B, Baron-Cohen S, Ashwin E, Knickmeyer R, Taylor K, Hackett G. Fetal testosterone and autistic traits. Br J Psychol Lond Engl. 2009;100(Pt 1):1-22.

5. Noor A, Whibley A, Marshall CR, Gianakopoulos PJ, Piton A, Carson AR, et al. Disruption at the PTCHD1 Locus on Xp22.11 in Autism spectrum disorder and intellectual disability. Sci Transl Med. 2010;2(49):49ra68.

6. Masi A, DeMayo MM, Glozier N, Guastella AJ. An overview of autism spectrum disorder, heterogeneity and treatment options. Neurosci Bull. 2017;33(2):183-93.

7. Chaste P, Leboyer M. Autism risk factors: genes, environment, and geneenvironment interactions. Dialogues Clin Neurosci. 2012;14(3):281-92.

8. Bohm HV, Stewart MG. Brief report: on the concordance percentages for Autistic Spectrum Disorder of twins. J Autism Dev Disord. 2009;39(5):806-8.

9. Vorstman JAS, Parr JR, Moreno-De-Luca D, Anney RJL, Nurnberger IJ Jr, Hallmayer JF. Autism genetics: opportunities and challenges for clinical translation. Nat Rev Genet. 2017;18(6):362-76.
10. Guang S, Pang N, Deng X, Yang L, He F, Wu L, et al. synaptopathology involved in autism spectrum disorder. Front Cell Neurosci. 2018;12:470.

11. Wang X, Kery R, Xiong Q. Synaptopathology in autism spectrum disorders: complex effects of synaptic genes on neural circuits. Prog Neuropsychopharmacol Biol Psychiatry. 2018;84:398-415.

12. Luo J, Norris RH, Gordon SL, Nithianantharajah J. Neurodevelopmental synaptopathies: insights from behaviour in rodent models of synapse gene mutations. Prog Neuropsychopharmacol Biol Psychiatry. 2018:84:424-39.

13. Durand CM, Betancur C, Boeckers TM, Bockmann J, Chaste P, Fauchereau $F$, et al. Mutations in the gene encoding the synaptic scaffolding protein SHANK3 are associated with autism spectrum disorders. Nat Genet. 2007:39(1):25-7.

14. Betancur C, Buxbaum JD. SHANK3 haploinsufficiency: a "common" but underdiagnosed highly penetrant monogenic cause of autism spectrum disorders. Mol Autism. 2013;4(1):17.

15. Leblond CS, Nava C, Polge A, Gauthier J, Huguet G, Lumbroso S, et al. Meta-analysis of SHANK Mutations in Autism Spectrum Disorders: a gradient of severity in cognitive impairments. PLoS Genet. 2014;10(9):e1004580.

16. Monteiro P, Feng G. SHANK proteins: roles at the synapse and in autism spectrum disorder. Nat Rev Neurosci. 2017;18(3):147-57.

17. Kouser M, Speed HE, Dewey CM, Reimers JM, Widman AJ, Gupta N, et al. Loss of predominant Shank3 isoforms results in hippocampus-dependent impairments in behavior and synaptic transmission. J Neurosci Off J Soc Neurosci. 2013;33(47):18448-68.

18. Duffney LJ, Zhong P, Wei J, Matas E, Cheng J, Qin L, et al. Autism-like deficits in Shank3-deficient mice are rescued by targeting actin regulators. Cell Rep. 2015;11(9):1400-13.

19. Qin L, Ma K, Wang Z-J, Hu Z, Matas E, Wei J, et al. Social deficits in Shank3deficient mouse models of autism are rescued by histone deacetylase (HDAC) inhibition. Nat Neurosci. 2018;21 (4):564-75.

20. Ma K, Qin L, Matas E, Duffney LJ, Liu A, Yan Z. Histone deacetylase inhibitor MS-275 restores social and synaptic function in a Shank3deficient mouse model of autism. Neuropsychopharmacology. 2018:43(8):1779-88.

21. Wang X, McCoy PA, Rodriguiz RM, Pan Y, Je HS, Roberts AC, et al. Synaptic dysfunction and abnormal behaviors in mice lacking major isoforms of Shank3. Hum Mol Genet. 2011;20(15):3093-108.

22. Jaramillo TC, Speed HE, Xuan Z, Reimers JM, Escamilla CO, Weaver TP, et al. Novel Shank3 mutant exhibits behaviors with face validity for autism and altered striatal and hippocampal function: Shank3 Exon 13 Mutant Autism Model. Autism Res. 2017;10(1):42-65.

23. Jaramillo TC, Xuan Z, Reimers JM, Escamilla CO, Liu S, Powell CM. Early restoration of Shank3 expression in Shank3 knock-out mice prevents core ASD-like behavioral phenotypes. eNeuro. 2020. https://doi.org/10.1523/ ENEURO.0332-19.2020.

24. Speed HE, Kouser M, Xuan Z, Reimers JM, Ochoa CF, Gupta N, et al. Autism-associated insertion mutation (InsG) of Shank3 Exon 21 causes impaired synaptic transmission and behavioral deficits. J Neurosci Off J Soc Neurosci. 2015;35(26):9648-65.

25. Drapeau E, Riad M, Kajiwara Y, Buxbaum JD. Behavioral phenotyping of an improved mouse model of Phelan-McDermid syndrome with a complete deletion of the Shank3 gene. eNeuro. 2018. https://doi.org/10.1523/ ENEURO.0046-18.2018.

26. Jaramillo TC, Speed HE, Xuan Z, Reimers JM, Liu S, Powell CM. Altered striatal synaptic function and abnormal behaviour in Shank3 Exon4-9 deletion mouse model of autism. Autism Res Off J Int Soc Autism Res. 2016;9(3):350-75

27. Mei Y, Monteiro P, Zhou Y, Kim J-A, Gao X, Fu Z, et al. Adult restoration of Shank3 expression rescues selective autistic-like phenotypes. Nature. 2016;530(7591):481-4.

28. Al Sagheer T, Haida O, Balbous A, Francheteau M, Matas E, Fernagut P-O, et al. Motor impairments correlate with social deficits and restricted neuronal loss in an environmental model of autism. Int J Neuropsychopharmacol. 2018;21:871-82.

29. Haida O, Al Sagheer T, Balbous A, Francheteau M, Matas E, Soria F, et al. Sex-dependent behavioral deficits and neuropathology in a maternal immune activation model of autism. Transl Psychiatry. 2019;9(1):124. 
30. Woodruff-Pak DS. Stereological estimation of Purkinje neuron number in C57BL/6 mice and its relation to associative learning. Neuroscience. 2006;141(1):233-43.

31. Franklin KBJ, Paxinos G. The mouse brain in stereotaxic coordinates. London: Academic Press; 2008.

32. Yang M, Silverman JL, Crawley JN. Automated three-chambered social approach task for mice. Curr Protoc Neurosci. 2011;Chapter 8:Unit 8.26.

33. Kalueff AV, Stewart AM, Song C, Berridge KC, Graybiel AM, Fentress JC. Neurobiology of rodent self-grooming and its value for translational neuroscience. Nat Rev Neurosci. 2016;17(1):45-59.

34. Fournier KA, Hass CJ, Naik SK, Lodha N, Cauraugh JH. Motor coordination in autism spectrum disorders: a synthesis and meta-analysis. J Autism Dev Disord. 2010;40(10):1227-40.

35. Fleming SM, Ekhator OR, Ghisays V. Assessment of sensorimotor function in mouse models of Parkinson's disease. J Vis Exp. 2013;76:50303.

36. Yirmiya N, Charman T. The prodrome of autism: early behavioral and biological signs, regression, peri- and post-natal development and genetics: autism prodrome. J Child Psychol Psychiatry. 2010;51(4):432-58.

37. Lakes EH, Allen KD. Gait analysis methods for rodent models of arthritic disorders: reviews and recommendations. Osteoarthr Cartil. 2016;24(11):1837-49.

38. Pierce $\mathrm{K}$, Courchesne E. Evidence for a cerebellar role in reduced exploration and stereotyped behavior in autism. Biol Psychiatry. 2001:49(8):655-64.

39. Voogd J, Schraa-Tam CKL, van der Geest JN, De Zeeuw Cl. Visuomotor cerebellum in human and nonhuman primates. Cerebellum Lond Engl. 2012;11(2):392-410

40. Bailey A, Luthert P, Dean A, Harding B, Janota I, Montgomery M, et al. A clinicopathological study of autism. Brain J Neurol. 1998;121(Pt 5):889-905

41. Wegiel J, Flory M, Kuchna I, Nowicki K, Ma SY, Imaki H, et al. Stereological study of the neuronal number and volume of 38 brain subdivisions of subjects diagnosed with autism reveals significant alterations restricted to the striatum, amygdala and cerebellum. Acta Neuropathol Commun. 2014;2:141

42. Tsai PT, Rudolph S, Guo C, Ellegood J, Gibson JM, Schaeffer SM, et al. Sensitive periods for cerebellar-mediated autistic-like behaviors. Cell Rep. 2018;25(2):357-367.e4

43. Ehlers MD. Synapse structure: glutamate receptors connected by the shanks. Curr Biol CB. 1999;9(22):R848-850.

44. Lee K, Vyas Y, Garner CC, Montgomery JM. Autism-associated Shank3 mutations alter mGluR expression and mGluR-dependent but not NMDA receptor-dependent long-term depression. Synapse. 2019;73(8):e22097.

45. Moretto E, Murru L, Martano G, Sassone J, Passafaro M. Glutamatergic synapses in neurodevelopmental disorders. Prog Neuropsychopharmacol Biol Psychiatry. 2018;84(Pt B):328-42.

46. Jiang $\mathrm{Y}-\mathrm{H}$, Ehlers MD. Modeling autism by SHANK gene mutations in mice. Neuron. 2013;78(1):8-27.

47. Wilson HL, Wong ACC, Shaw SR, Tse W-Y, Stapleton GA, Phelan MC, et al. Molecular characterisation of the 22q13 deletion syndrome supports the role of haploinsufficiency of SHANK3/PROSAP2 in the major neurological symptoms. J Med Genet. 2003;40(8):575-84.

48. Naisbitt S, Kim E, Tu JC, Xiao B, Sala C, Valtschanoff J, et al. Shank, a novel family of postsynaptic density proteins that binds to the NMDA receptor/ PSD-95/GKAP complex and cortactin. Neuron. 1999;23(3):569-82.
49. Kloth AD, Badura A, Li A, Cherskov A, Connolly SG, Giovannucci A, et al. Cerebellar associative sensory learning defects in five mouse autism models. eLife. 2015;4:e06085.

50. American Psychiatric Association. Diagnostic and statistical manual of mental disorders. 5th ed. Arlington: American Psychiatric Association: 2013.

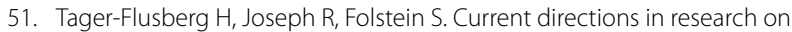
autism. Ment Retard Dev Disabil Res Rev. 2001;7(1):21-9.

52. Fatemi SH, Aldinger KA, Ashwood P, Bauman ML, Blaha CD, Blatt GJ, et al. Consensus paper: pathological role of the cerebellum in autism. Cerebellum Lond Engl. 2012;11(3):777-807.

53. Ozonoff S, Young GS, Goldring S, Greiss-Hess L, Herrera AM, Steele J, et al. Gross motor development, movement abnormalities, and early identification of autism. J Autism Dev Disord. 2008;38(4):644-56.

54. Hallett M, Lebiedowska MK, Thomas SL, Stanhope SJ, Denckla MB, Rumsey J. Locomotion of autistic adults. Arch Neurol. 1993;50(12):1304-8.

55. Stolze H, Klebe S, Petersen G, Raethjen J, Wenzelburger R, Witt K, et al. Typical features of cerebellar ataxic gait. J Neurol Neurosurg Psychiatry. 2002;73(3):310-2

56. Rinehart NJ, Tonge BJ, lansek R, McGinley J, Brereton AV, Enticott PG, et al. Gait function in newly diagnosed children with autism: cerebellar and basal ganglia related motor disorder. Dev Med Child Neurol. 2006;48(10):819-24.

57. Gong L, Liu Y, Yi L, Fang J, Yang Y, Wei K. Abnormal gait patterns in autism spectrum disorder and their correlations with social impairments: abnormal gait patterns in autism. Autism Res. 2020;13(7):1215-26.

58. Vicidomini C, Ponzoni L, Lim D, Schmeisser MJ, Reim D, Morello N, et al. Pharmacological enhancement of $\mathrm{mGlu} 5$ receptors rescues behavioral deficits in SHANK3 knock-out mice. Mol Psychiatry. 2017;22(5):689-702.

59. Tu Z, Zhao H, Li B, Yan S, Wang L, Tang Y, et al. CRISPR/Cas9-mediated disruption of SHANK3 in monkey leads to drug-treatable autism-like symptoms. Hum Mol Genet. 2019;28(4):561-71.

60. Carlson GC. Glutamate receptor dysfunction and drug targets across models of autism spectrum disorders. Pharmacol Biochem Behav. 2012;100(4):850-4.

61. Bozdagi O, Sakurai T, Papapetrou D, Wang X, Dickstein DL, Takahashi N, et al. Haploinsufficiency of the autism-associated Shank3 gene leads to deficits in synaptic function, social interaction, and social communication. Mol Autism. 2010;1(1):15.

62. Peça J, Feliciano C, Ting JT, Wang W, Wells MF, Venkatraman TN, et al. Shank3 mutant mice display autistic-like behaviours and striatal dysfunction. Nature. 2011:472(7344):437-42.

63. Schmeisser MJ. Translational neurobiology in Shank mutant micemodel systems for neuropsychiatric disorders. Ann Anat Anat Anz. 2015;200:115-7.

64. Bey AL, Jiang Y. Overview of mouse models of autism spectrum disorders. Curr Protoc Pharmacol. 2014;66:5-66.

\section{Publisher's Note}

Springer Nature remains neutral with regard to jurisdictional claims in published maps and institutional affiliations.

Ready to submit your research? Choose BMC and benefit from

- fast, convenient online submission

- thorough peer review by experienced researchers in your field

- rapid publication on acceptance

- support for research data, including large and complex data types

- gold Open Access which fosters wider collaboration and increased citations

- maximum visibility for your research: over 100M website views per year

At BMC, research is always in progress.

Learn more biomedcentral.com/submissions 